Verónica Baudino, Alianzas y rupturas políticas entre capitalistas industriales durante el tercer gobierno peronista (1973-1976), Izquierdas, 40, junio 2018:82-100

\title{
Alianzas y rupturas políticas entre capitalistas industriales durante el tercer gobierno peronista (1973-1976)
}

\author{
Alliances and political ruptures of the Argentine bourgeoisie during the third \\ Peronist Government (1974-1976)
}

Verónica Baudino*

Resumen: El presente artículo tiene por fin intentar reconstruir la conformación y en especial, la descomposición de la alianza entre la Confederación General Económica (CGE) y la Unión Industrial Argentina (UIA), en tiempos del tercer gobierno peronista. Observaremos la experiencia de unificación de ambas entidades que dio forma a la Confederación Industrial Argentina (CINA), que actuó entre 1974 y 1976, hasta su desaparición luego del golpe de Estado. Atenderemos a la crisis y la descomposición de la CGE debido la constitución de una oposición interna y externa a su dirección nacional. La conformación de una alianza de industriales de tendencias reformistas (aún compuesta por actores históricamente enfrentados a expresiones peronistas) aconteció en una tendencia económica ascendente que abría posibilidades a la reproducción de un conjunto mayor de capitales débiles, sumado a las necesidades de la clase dominante de frenar el proceso insurreccional de masas iniciado en mayo de 1969. La reactualización de la crisis económica en 1974, reavivó los enfrentamientos entre los distintos sectores de la burguesía por una ganancia en baja y asestó un golpe a la política reformista. Un nuevo ciclo de alza de la lucha de los trabajadores en oposición a las políticas de ajuste, constituyó el detonante de la constitución de la alianza golpista que accionó para quebrar la fuerza reformista y sumarla a su proyecto represivo de recomposición de las condiciones normales de reproducción del capitalismo argentino.

Palabras clave: Historia, Peronismo, capitalistas industriales, golpe de estado

Abstract: This article intends to reconstruct the shape and in particular the
breakdown of the alliance between the General Economic Confederation (CGE) and
the Union Industrial Argentina (UIA), in times of third Peronist government. We
study the experience of unification of both entities Argentina Industrial Confederation
(CINA), between 1974 and 1976 . We will analyze the crisis and breakdown of the
CGE, as a result of the failure of his policy of conciliation. Rebuild the internal and

* Argentina, Doctora en Historia, IDIHCS-CONICET, veronicabaudino@ yahoo.com.ar 
Verónica Baudino, Alianzas y rupturas políticas entre capitalistas industriales durante el tercer gobierno peronista (1973-1976), Izquierdas, 40, junio 2018:82-100

external opposition to the national leadership of the General Economic Confederation. Our hypothesis is that the formation of an alliance of industrial in this period is part of an economic trend that opened up possibilities for breeding to a larger set of weak capital, coupled with the needs of the ruling class to stop the mass insurrectionary process begun in May 1969. The updating of the economic crisis in 1974 revived the fighting between the various sectors of the bourgeoisie and exposed the limits of reformist politics. A new cycle of escalating struggle of workers in opposition to the policies of adjustment, was the trigger for the formation of the alliance coup.

Key words: History, Peronismo, industrial bourgeoisie, coup d'état

Recibido: 27 septiembre 2017

Aceptato: 22 noviembre 2017

\section{Introducción}

La década de 1970, convulsionada por al auge de las luchas populares a nivel mundial tuvo su correlato en Argentina. Las grandes insurrecciones de masas de 1969 denominadas Cordobazo y Rosariazo en alusión a las ciudades que se constituyeron como su escenario, abrieron un ciclo de progresiva ruptura de los lazos políticos que unían a ciertos sectores de la clase obrera con la burguesía nacional. Así un sector importante de la clase obrera pasó a organizarse en torno a programas articulados en un proyecto de superación del modo de producción capitalista, escindidos en múltiples tendencias políticas $^{2}$.

El regreso del peronismo ${ }^{3}$ al gobierno, el 25 de mayo de 1973, luego de dos décadas de proscripción significó un impasse en el curso del movimiento insurreccional, canalizando por la vía institucional parte del descontento expresado desde las jornadas de 1969. El éxito, aunque como veremos momentáneo, de la política del tercer gobierno consistió en su tinte reformista que, asentado en el fuerte incremento de la renta de la tierra $^{4}$, contemplaba un incremento en la distribución de riquezas hacia los capitales

\footnotetext{
2 Beba Balvé Beatriz y Beatríz Balvé, El'69 huelga política de masas: rosariazo, Cordobazo, rosariazo. Razón y Revolución-CICSO, 2005; James Brennan, El Cordobazo, Sudamericana, Buenos Aires. 1996.

${ }^{3}$ El peronismo ha sido objeto de muchos estudios y definiciones. Ver entre otros: Liliana De Riz, Retorno y derrumbe: el último gobierno peronista. Vol. 75. Hyspamerica, 1987; Mónica Peralta-Ramos, La economía política argentina: poder y clases sociales, 1930-2006. Fondo De Cultura Económica USA, 2007.

${ }^{4}$ Nos apoyamos en las consideraciones acerca de la renta de la tierra estudiadas en Juan Iñigo Carrera, La formación económica de la sociedad argentina, Imago Mundi, Buenos Aires, 2007, sin desconocer el profuso debate al respecto.
} 
Verónica Baudino, Alianzas y rupturas políticas entre capitalistas industriales durante el tercer gobierno peronista (1973-1976), Izquierdas, 40, junio 2018:82-100

individuales más pequeños y la clase trabajadora ${ }^{5}$. Este proyecto fue impulsado y apoyado, al menos en su primera etapa, por las corporaciones empresarias objeto de este estudio: la Confederación General Económica (CGE) y la Unión Industrial Argentina (UIA). La primera de ellas ha sido caracterizada como una corporación de empresarios pequeños de origen nacional ${ }^{6}$, mientras que la Unión Industrial Argentina agrupaba en ese entonces a pequeños, medianos y grandes empresarios a escala nacional, de origen argentino y extranjero ${ }^{7}$. El presente artículo tiene por fin intentar reconstruir la conformación y en especial, la descomposición de la alianza política entre los capitales individuales nucleados en ambas entidades, históricamente enfrentadas en programas aparentemente antagónicos, hasta su breve fusión durante el tercer gobierno peronista.

\section{Debate historiográfico}

La mirada acerca de la participación de la burguesía en el retorno del peronismo ha dado centralidad a la participación de la $\mathrm{CGE}^{8}$. Su activo apoyo se manifestó en que la política rectora del tercer gobierno peronista, el "Pacto Social", impulsado en 1973 tenía como vértebra principal a la CGE, tanto por su diseño programático como por el personal político que lo llevó adelante con José Ver Gelbard (presidente de la CGE) a la cabeza ${ }^{9}$. En caso de poner en relieve otros apoyos burgueses al gobierno iniciado en 1973, como los de la UIA o Sociedad Rural Argentina (SRA), los trabajos especializados interpretan que se trato de mero oportunismo, aunque la historia da cuenta de un proceso mucho más complejo vinculado a un viraje político que llevaba años procesándose.

\footnotetext{
${ }^{5}$ Caracterizamos la política económica implementada al menos en el primer momento del tercer gobierno peronista como reformista, sin desconocer las miradas del peronismo como fenómeno centradas en las nociones "populismo", "bonapartismo" y "revolución" (Ernesto Laclau, "Hacia una teoría del populismo", E. Laclau, Política e ideología en la teoría marxista. Capitalismo, fascismo, populismo. Madrid. Siglo Veintiuno, 1978; Ricardo Sidicaro, "Consideraciones sociológicas sobre las relaciones entre el peronismo y la clase obrera en Argentina, 1943-1955”, Moira Mackinnon y Mario Alberto Petrone [comps.], Populismo y neopopulismo, el problema de la Cenicienta. Buenos Aires. Eudeba, 1998; Aberlardo Ramos, La era del peronismo, 1943-1989, Buenos Aires, Ediciones del Mar Dulce, 1990; Rodolfo Puiggrós, El peronismo: sus causas, Buenos Aires, Cepe, 1972; Milcíades Peña, “Apuntes para una historia del peronismo. El gobierno del 'como si': 1946- 1955”, Revista Fichas de Investigación Económica y Social, nro. 7, 1965, pp. 3-21.)

${ }^{6}$ José Luis De Ímaz, Los que mandan, Eudeba, Buenos Aires, 1965; Roque Caggiano, Notas sobre el desarrollo de la burguesía nacional: La Confederación General de la Industria y la Unión Industrial en el período 1957-1973, Centro de Estudios Urbanos y Regionales, Instituto Torcuato Di Tella, 1975; John William Freels, El sector industrial en la política nacional, EUDEBA, Editorial Universitaria de Buenos Aires, 1970; , Claudio Belini, Convenciendo al capital: Peronismo, burocracia, empresarios y política industrial, 1943-1955, Ediciones Imago Mundi, 2014; Verónica Baudino, La estrategia de la UIA 1966-1976, Tesis doctoral, Facultad de Filosofía y Letras de la UBA, 2012; Javier Lindenboim, "El empresariado industrial argentino y sus organizaciones gremiales entre 1930 y 1946." Desarrollo Económico 16.62 (1976): 163-201.

${ }^{7}$ Jorge Schvarzer, Empresarios del pasado: la Unión industrial argentina. Buenos Aires: Cisea, 1991.

${ }^{8}$ James Brennan y Marcelo Rougier, Perón y la burguesía argentina. El proyecto de un capitalismo nacional y sus límites (1946-1976), Editorial Lenguaje Claro, Buenos Aires, 2013; Alejandro. Horowicz, Los cuatro peronismos, Edhasa, Buenos Aires, 2007; Daniel Muchnik, Argentina modelo: de la furia a la resignación: economía y política entre 1973 y 1998. Ediciones Manantial, 1998; Carlos Leyba, Economía y política en el tercer gobierno de Perón. Editorial Biblos, 2003; Guido Di Tella y Luis Justo, Perón-Perón, 1973-1976. Editorial Sudamericana, 1983.

${ }^{9}$ Marcelo Rougie y Martín Fiszbein. La frustración de un proyecto económico: el gobierno peronista de 1973-1976. Ediciones Manantial, 2006.
} 
Verónica Baudino, Alianzas y rupturas políticas entre capitalistas industriales durante el tercer gobierno peronista (1973-1976), Izquierdas, 40, junio 2018:82-100

La reactualización de la crisis económica en 1974, reavivó los enfrentamientos entre los distintos sectores de la burguesía por una ganancia en baja y puso en evidencia los límites de la política reformista. Un nuevo ciclo de alza de la lucha de los trabajadores en oposición a las políticas de ajuste, constituyó el detonante de la constitución de la alianza golpista que accionó para quebrar la alianza política reformista y sumarla a su proyecto represivo. La bibliografía ha enfatizado en la acción de la SRA, Bolsa de Comercio y capitales socios de la UIA ${ }^{10}$ así como en think tanks como la Fundación Mediterránea, CEMA y FIEL ${ }^{11}$. Pero no se profundizó suficientemente en la confluencia progresiva de pequeños y medianos capitales industriales con la estrategia militar. Ha operado una exclusión del campo de interés del proceso de conformación de la alianza golpista que derroca al peronismo el 24 de marzo de 1976 a los capitalistas pertenecientes a la CGE. Consideramos por este motivo necesario la reconstrucción del proceso que culmina en el golpe militar, dando cuenta de las alianzas tejidas y sus integrantes.

\section{Metodología}

En función del objetivo general de nuestro trabajo, observaremos la experiencia de unificación de ambas entidades que dio forma a la Confederación Industrial Argentina (CINA) como órgano de la CGE, que actuó entre 1974 y 1976, hasta su desaparición luego del golpe de estado. Atenderemos a la crisis y la descomposición de la CGE en tanto corporación burguesa ${ }^{12}$, como resultado del fracaso de su política adecuada al momento de auge económico y relativa baja de la conflictividad social, una vez revertida esa tendencia. Reconstruiremos la oposición interna y externa a la dirección nacional de la CGE. La conformación de una alianza de industriales reformistas parece haberse enmarcado en una tendencia económica ascendente que abría posibilidades a la reproducción a un conjunto mayor de capitales débiles, sumado a las necesidades de la clase dominante de frenar el proceso insurreccional de masas iniciado en mayo de 1969; que evidenció prontamente sus límites una vez que las condiciones económicas y políticas se movieron hacia su dirección opuesta.

Las fuentes utilizadas son principalmente de circulación periódica (La Nación, Clarín y Cronista Comercial). En el presente trabajo se han escogido mayormente citas de La Nación por dar cuenta día a día del proceso que intentamos analizar. De todas formas,

\footnotetext{
${ }^{10}$ Mirta Palomino, "Tradición y poder: La sociedad rural argentina (1955-1983). Buenos Aires: CISEA/Grupo Editor Latinoamericano, 1988; Carlos H. Acuña, "Las contradicciones de la burguesía en el centro de la lucha entre el autoritarismo y la democracia (1955-1983)". Realidad Económica, no. 138 (1996), p. 18-48.

${ }^{11}$ Hernán Ramírez, Corporaciones en el poder. Institutos y acción política en Brasil y Argentina. IPÊE, FIEL y Fundación Mediterránea, Lenguaje Claro Editora, Buenos Aires, 2007; Mariana Heredia, "El proceso como bisagra. Emergencia y consolidación del liberalismo tecnocrático: FIEL, FM y CEMA." Alfredo Pucciarelli (dir.), Empresarios, tecnócratas y militares. La trama corporativa de la última dictadura. Buenos Aires: Siglo XXI, 2004.

${ }^{12}$ Denominamos corporación burguesa en tanto se orienta a expresar la acción política de uno o varios sectores de la clase capitalista (capital personificado - Marx. Karl. El Capital, Siglo XIX, Buenos Aires, 2002.) que la integran frente al Estado (Elmar Altvater, "Estado y capitalismo. Notas sobre algunos problemas del intervencionismo estatal." Cuadernos políticos 9 (1976): 1950-1980), frente a otras corporaciones de capitalistas y a los sindicatos de trabajadores.
} 
Verónica Baudino, Alianzas y rupturas políticas entre capitalistas industriales durante el tercer gobierno peronista (1973-1976), Izquierdas, 40, junio 2018:82-100

la información ha sido chequeada, en la medida de lo posible, con el resto de las publicaciones periódicas consultadas. Por otra parte, las fuentes institucionales accesibles (Memoria y Balance de la UIA y CGE, Revista de la UIA, Boletín Informativo de la CGE, Congreso General de la Industria, Publicaciones del Instituto Investigaciones Económicas y Financieras), no dan cuenta de las numerosas acciones de la entidad y sus diferentes miembros, y mucho menos el detalle de las discordancias internas y el proceso de ruptura de ciertas federaciones económicas y sus causas.

\section{Pacto social y unificación política de la burguesía}

En plan económico desarrollado durante el tercer gobierno peronista fue elaborado por la CGE, y llevado adelante por su más representativo dirigente, José Ber Gelbard. Una coyuntura de auge de los precios internacionales de las mercancías agropecuarias ${ }^{13}$ constituyó la base material de la experiencia reformista. Uno de los mecanismos privilegiados para captar la renta y transferirla hacia los pequeños capitales y la clase obrera fue la intervención estatal en el comercio exterior e interior de productos agropecuarios. A través de la centralización de la producción y su venta mediante organismos oficiales, el Estado tomaba una porción de la renta pagando precios menores a la cotización internacional de los productos. Las retenciones a las exportaciones y una sobrevaluación del peso del orden del $45 \%$ completaban los mecanismos de captación de renta por parte del Estado. Los subsidios y créditos promocionados constituyeron las principales vías en que la renta captada por el Estado iba a parar al ineficiente entramado industrial.

Pero la iniciativa más importante encarada por Gelbard fue el acuerdo entre una fracción del empresariado y las cúpulas sindicales, destinado a contener la inflación. El compromiso, denominado "Pacto Social", fue suscripto por la Confederación General del Trabajo (CGT) y la CGE, y fue aprobado por el conjunto de la burguesía industrial, aunque más no sea formalmente. A partir de la firma del "Pacto Social", los empresarios se comprometieron a no aumentar los precios y los dirigentes sindicales a no encarar luchas por aumentos salariales. Sin embargo, este acuerdo tenía implicancias que trascendían los objetivos económicos: el cerrojo que se imponía sobre los conflictos salariales apuntaba no solo a contener la inflación, sino a aquietar las aguas de la conflictividad obrera.

La reinstauración de la democracia bajo la dirección política de Perón parece haber condicionado fuertemente a la UIA, que terminó por encolumnarse tras su proyecto. La victoria electoral abrumadora evidenciaba la necesidad estratégica de alinearse con el gobierno en su objetivo común de desarticular la lucha revolucionaria y restablecer la acumulación de capital. No había muchas alternativas en el clima insurreccional que se vivía en los primeros años de la década de 1970. A su vez, el contexto económico favorable hacía posible materializar las transferencias de ingreso de las que buena parte de

\footnotetext{
${ }^{13}$ Juan Iñigo Carrera, op.cit.
} 
Verónica Baudino, Alianzas y rupturas políticas entre capitalistas industriales durante el tercer gobierno peronista (1973-1976), Izquierdas, 40, junio 2018:82-100

la burguesía industrial se beneficiaría. La existencia de ciertos sectores de la UIA proclives a la unificación con la CGE, parecen haber operado en dicha dirección ${ }^{14}$. De hecho, todo un espectro de socios amenazó con independizarse de la corporación industrial debido a la defensa de la dirección nacional de políticas concentradoras, y el mantenimiento de alianzas de corte liberal en el marco de la Acción Coordinadora de Instituciones Empresarias Libres (ACIEL) ${ }^{15}$. La dirección de la UIA tuvo que ceder ante la inminente ruptura de un sector importante de su base social que amenazaba con alinearse a la CGE. Este riesgo obligó asimismo a quebrar la alianza liberal con ACIEL (Memoria y Balance de la UIA, 1974). Esta ruptura tuvo como punto nodal la discusión sobre aumentos salariales. Mientras la Sociedad Rural Argentina (perteneciente a ACIEL) sostenía que no debía hacerse lugar a las subas, la UIA declaraba era necesario un incremento salarial para motorizar el mercado interno. La discusión se tornó irreconciliable entre los miembros de ACIEL, provocando el alejamiento de la UIA de aquel espacio corporativo. La diferencia programática entre líneas reformistas versus liberal-concentradoras marcó la ruptura de una alianza que se sostenía desde 1958. Así, la fuerza de atracción de la estrategia reformista en un contexto aparentemente propicio para su desarrollo, sumada a la posibilidad de neutralizar la amenaza revolucionaria constriñeron a la dirección de la UIA a tomar, aunque sea momentáneamente, el rumbo del peronismo. De hecho, la UIA se incorporó en 1974 a la CGE. ${ }^{16}$

La fusión tuvo como precedente el acta firmada en el verano de 1974, donde la UIA y la CGE manifestaron "su coincidencia con los objetivos generales enunciados en materia económica por el superior gobierno y con los propósitos que han originado el Acta de Compromiso Nacional" "17. El 29 de abril de ese año quedó ratificada la vocación de unificación empresaria al elegirse como miembros del Consejo Superior de la CGE a dirigentes de la UIA. Martín Noel, de la firma Noel y Cía., ex secretario de la UIA, ocupó el cargo de secretario en la CGE. Roberto Blanco, perteneciente a la empresa Elfapel, ex vocal suplente de la UIA, asumió como protesorero; Miguel Teubal, de la empresa homónima, ocupó el puesto de presidente de la Comisión de Política Crediticia.

El 3 de julio de 1974, la UIA y la Confederación General Industrial ${ }^{18}$ quedaron fusionadas en la CINA, que se constituyó en la "pata industrial" de la CGE. La Junta Directiva de la entidad quedó conformada en su mayoría por dirigentes de la UIA: Vicepresidente $1^{\circ}$, Eduardo Braun Cantilo, Vicepresidente $2^{\circ}$, Roberto Favelic, Vicepresidente $3^{\circ}$, Edmundo Paul, Pro-secretario $1^{\circ}$, Elías Ramírez. Por parte de la CGI:

\footnotetext{
${ }^{14}$ Baudino, Verónica, op.cit.

${ }^{15}$ ACIEL fue una mega corporación fundada en 1958 para contrarrestar la influencia política de la Confederación General. Reunía a las fracciones más concentradas de la burguesía industrial, rural, comercial y financiera argentina y la extranjera que operaba en este espacio nacional, nucleadas en Sociedad Rural Argentina, la Corporación Argentina de Comercio, La Bolsa de Comercio y a la UIA, entre otras.

${ }^{16}$ Memoria y Balance de la CGE, 1974.

${ }^{17}$ La Nación, 23 de febrero de 1974.

${ }^{18}$ Confederación General Industrial era un nucleamiento de industriales de la CGE antes de la unificación con la UIA. Formaban parte de la misma la Confederación General de la Industria, la Confederación General de la Producción y la Confederación General del Comercio.
} 
Verónica Baudino, Alianzas y rupturas políticas entre capitalistas industriales durante el tercer gobierno peronista (1973-1976), Izquierdas, 40, junio 2018:82-100

Rafael Kohanoff, como Vice $4^{\text {o; }}$ Pablo Romay, como secretario y Juan A. Pereyra como pro-secretario $2^{\circ}$. La presidencia de la entidad fue otorgada a Carlos Coquegniot, miembro de la ADIC (Asociación de Industriales de Córdoba) ${ }^{19}$. Esta entidad había expresado tendencias reformistas, y acaudillado a un importante número de socios de la UIA contra su dirección nacional.

El presidente de la nueva entidad justificó la unión como un acto que tenía presentes "los superiores intereses de la Nación, que necesita alcanzar su plena independencia, de integración, de auténtica representatividad y de solidaridad social" ${ }^{20}$. En el primer plenario luego de la unificación de las entidades empresariales se acordó un documento en defensa del gobierno de Perón, llamando al conjunto de los empresarios a apoyarlo.

Así, el peronismo actuaba como unificador de dos fracciones de la burguesía históricamente enfrentadas en estrategias políticas diferentes. ${ }^{21}$ La reconstitución de la alianza de carácter reformista impulsada por la CGE, avivó disputas internas en la UIA que iniciaron un camino de ruptura con la estrategia concentradora (o liberal) encarnada en la dirección nacional. ${ }^{22}$ Dicho movimiento interno constituyó el fundamento social de la unificación de la UIA y la CGE en una central que obrara como apoyo burgués al retorno del peronismo en un contexto económico propicio base de la articulación de políticas capaces de frenar el desarrollo de las tendencias insurreccionales de la clase obrera.

\section{La crisis del Pacto Social}

La muerte de Perón y la asunción de Isabel Martínez, cambiaron el panorama para la recientemente fundada entidad. Poco tiempo después de la muerte del primer mandatario, en octubre de 1974, Isabel desplazó de su cargo a Gelbard reemplazándolo por Alfredo Gómez Morales. Su reemplazo respondía a conflictos políticos internos y a los síntomas de crisis económica que comenzaban a asomar en el horizonte. Habría que señalar, en primer lugar, que la principal medida impulsada por la gestión Gelbard, el intento de contener la escalada inflacionaria fijando mediante la concertación los precios y los salarios, había naufragado. Ni la CGT ni la CGE pudieron disciplinar a sus bases para sostener el acuerdo. Los sindicatos, empujados por dirigentes y delegados clasistas y muchas veces contra los designios de la conducción de la CGT, encontraron la forma de luchar por mejorar las condiciones de venta de su fuerza de trabajo sin violentar el Pacto Social. Así, entre 1973 y 1974, se extendieron las luchas exigiendo la disminución de la

\footnotetext{
${ }^{19}$ Baudino, Verónica, op.cit.; Schvarzer, Jorge, op.cit.

${ }^{20}$ La Nación, 3 de agosto de 1974.

${ }^{21}$ Guillermo O'donnell, op.cit.

${ }^{22}$ La estrategia denominada "liberal", a diferencia de la "reformista", aparece en momentos de contracción económica, recortando transferencias y en consecuencia eliminando capital sobrante. Ambos momentos se corresponden con los ciclos de renta de la tierra y endeudamiento, especificidad del capitalismo argentino (Juan Iñigo Carrera, op.cit.)
} 
Verónica Baudino, Alianzas y rupturas políticas entre capitalistas industriales durante el tercer gobierno peronista (1973-1976), Izquierdas, 40, junio 2018:82-100

intensidad de la jornada laboral, mejores condiciones de seguridad e higiene o reclamando premios a la productividad. Muchas veces, la presión y la organización obrera obtuvieron victorias, con lo que, a pesar de que no hubo aumentos salariales, aumentaron los costos laborales para las empresas. Por el lado empresario, los límites impuestos a los precios fueron burlados colocando los productos en el "mercado negro" e intensificando el desabastecimiento. ${ }^{23}$ A poco de andar, el Pacto Social era poco más que letra muerta. A este fracaso de la política de concertación, se sumaban las negras perspectivas en el mercado mundial. La crisis económica internacional comenzaba a afectar a la Argentina: los precios de las mercancías agrarias iniciaron una carrera descendente, mientras que los costos de las importaciones aumentaban, empujados por el alza internacional de los precios del petróleo. La política de Gelbard, que no tenía muchas herramientas para enfrentar aquellas perspectivas, ya había comenzado a suscitar la oposición de un número creciente de capitales individuales.

Veremos, a continuación, cómo comenzaron a agudizarse los reclamos de la CGE al gobierno nacional. A su vez, cómo empezaron a aflorar los enfrentamientos internos dentro de la entidad, entre quienes pretendían volver a la política de concertación y aquellos que presionaban para profundizar un ajuste, que ya se encontraba en la agenda, aún al costo de romper la alianza con los trabajadores y profundizar los aspectos represivos de la política oficial. En estas internas tendrán un lugar destacado los dirigentes provenientes de la UIA, que serán protagonistas de uno de los frentes de conflicto que enfrentaban el gobierno nacional y la dirección de la CGE.

La imposibilidad de contener los precios en medio de la crisis y las presiones de la movilización obrera obligaron al gobierno a llamar a una Gran Paritaria Nacional a principios de 1975, que marcó la agenda de la CGE en los meses subsiguientes. Reaparecía nuevamente el viejo problema de los salarios y la puja con la clase obrera, punto central de las intervenciones de la CGE y la CINA entre principios de 1975 y la consumación del golpe de estado en marzo de 1976.

En una reunión destinada a tratar los cursos de acción por seguirse ante la convocatoria a paritarias, los dirigentes de la CGE decidieron dirigir un mensaje al Ministro de Economía, al Ministerio de Bienestar Social y a la CGT, para solicitarles entrevistas urgentes. Asimismo, solicitaron entrevistarse con la Presidente de la Nación, considerando que estando en vigor el Acta del Compromiso Nacional, las convenciones colectivas de trabajo debían enmarcarse dentro de una política global de salarios, precios y nivel de vida, y para ello deseaban evaluar todas esas posibilidades con las autoridades nacionales y con la $\mathrm{CGT}^{24}$.

Una vez abiertas por decreto las paritarias, a fines de enero, la CGE solicitó una entrevista con el Ministro de Trabajo, Ricardo Otero, a fin de conocer los alcances del llamado a las comisiones. La CGE manifestó que había encontrado "la mejor

\footnotetext{
${ }^{24}$ La Nación, 11 de febrero de 1975.
} 
Verónica Baudino, Alianzas y rupturas políticas entre capitalistas industriales durante el tercer gobierno peronista (1973-1976), Izquierdas, 40, junio 2018:82-100

predisposición del empresariado nacional" y que "las bases para las negociaciones no tendrían ninguna limitación, ni siquiera en el aspecto salarial" 25 .

Mientras tanto, la CGT solicitó un aumento salarial de emergencia, como respuesta al deterioro del salario real, estimado en un $17 \%$ desde el último aumento de noviembre de 1974. La CGE propiciaba que este aumento se resuelva en el marco de la Gran Paritaria Nacional, lo que les daba la posibilidad de dilatarlo o morigerarlo. En cambio, la CGT aspiraba a un aumento fijo a establecerse por decreto del Poder Ejecutivo.

Por otro lado, la CGE y la CINA demandaron que, de convocarse a la Gran Paritaria, deberían tratarse no solo temas salariales, sino también del tipo de cambio (para facilitar exportaciones), precios relativos entre sector industrial y agropecuario, ausentismo y créditos $^{26}$. De esta manera, la CGE buscaba condicionar los aumentos salariales a compromisos gubernamentales y sindicales que los compensaran.

Finalmente, el $1^{\circ}$ de Marzo de 1975 se dispuso el aumento salarial por decreto, tal cómo lo exigía la CGT. A su vez, se establecieron medidas de control de precios, para evitar que los empresarios trasladaran el aumento de costos que implicaban las subas salariales a las mercancías. La CGE criticó la resolución de la Secretaría de Comercio, a la que calificó como un "congelamiento de precios", alegando, a su vez, que la misma no había respetado las pautas de la política de concertación. El ministro de Economía manifestó que dicha medida no implicaba congelamiento (aunque de hecho lo era), y que sólo constituía un nuevo mecanismo de control para que los aumentos salariales no se trasladen a los precios. Así mismo señaló que dicha medida estaba implícita en lo acordado por al Gran Paritaria Nacional.

Otro de los problemas surgidos del naufragio de la política de concertación fue el desabastecimiento. En este marco, la CGE convocó a sectores comerciales e industriales directamente vinculados a la producción y comercialización de productos para analizar las causas que afectaban los niveles de abastecimiento. Los sectores empresarios representados plantearon que debía alcanzarse la adecuación total de la ley de abastecimiento a la "realidad actual" y su conversión en un instrumento idóneo y flexible a la cambiante economía universal ${ }^{27}$. La CGE ataba el problema del desabastecimiento a la política oficial de control de precios, y exigía flexibilizar los controles y adecuar la normativa a una nueva realidad signada por una incipiente crisis inflacionaria y los aumentos salariales. En suma, la solución al desabastecimiento pasaba por permitir los aumentos de precios.

Más duramente intervino la Confederación Económica de la Provincia de Buenos Aires, adherida a la CGE, que impulsó un lock out como medida de protesta por la grave crisis del comercio minorista, medida que finalmente no se concretó ${ }^{28}$. Esta entidad solicitaba "la autorización para remarcar existencias a costos de reposición" a la vez que

\footnotetext{
${ }^{25}$ La Nación, 31 de enero de 1975.

${ }^{26}$ La Nación 13 de febrero de 1975.

${ }^{27}$ Clarín, 2 de abril de 1975.

${ }^{28}$ La Nación, 23 de abril de 1975.
} 
Verónica Baudino, Alianzas y rupturas políticas entre capitalistas industriales durante el tercer gobierno peronista (1973-1976), Izquierdas, 40, junio 2018:82-100

denunciaba, "el desabastecimiento, la intermediación innecesaria, o la aplicación excesiva de la ley de abastecimiento por parte de algunas municipalidades" 29 .

\section{El Fondo Empresario}

La decisión de crear un Fondo Empresario, en el marco de la Gran Paritaria Nacional de principios de 1975, financiado con un aporte del 1,5 por mil sobre los sueldos de todas las empresas nacionales, que se destinaría, en parte iguales, a la CGE y a la CGT, reavivó los enfrentamientos entre los distintos sectores de la burguesía. Las cámaras empresarias, comerciales y agrarias, ajenas a la CGE manifestaron su oposición. Y, más importante aún, la CGE, también asistió a enfrentamientos internos por esta cuestión, entre algunos sectores de la CINA y su dirección nacional.

La aprobación de la creación del Fondo por parte de la CGE habría disparado el reclamo de muchos de sus miembros, que aseguraban no haber sido consultados. Por esta razón, diversos asociados pertenecientes a la CINA comenzaron a organizar reuniones por ramas fabriles a fin estrechar relación entre los niveles dirigentes y las cámaras de la entidad. ${ }^{30}$ Se vivía un estado de deliberación, que preanunciaba futuros enfrentamientos entre los viejos enemigos de la UIA y de la CGI.

En los días que siguieron se sucedieron los ataques de diferentes organizaciones empresariales a la CGE. El consejo directivo de la Federación Industrial de la Provincia de Córdoba ratificó su pedido de intervención a la CGE nacional. La entidad manifestó su oposición al establecimiento de un aporte obligatorio mensual, ya que todos los empresarios pagaban, pero se beneficiaba exclusivamente a la CGE y la CGT. ${ }^{31}$ Declararon su disconformidad también la Cámara de la Construcción, CARTEZ (Confederación de Sociedades Rurales de la Tercera Zona), la Comisión de Enlace de Asociaciones Rurales de La Pampa, la Comisión de Entidades Empresarias de Primer Grado, la Asociación de Industrias Argentina de Carnes, la Federación del Comercio de la Ciudad de Buenos Aires, la Cámara de Grandes Tiendas y Anexos, la Cámara Argentina de Frigoríficos, Industriales y Exportadores de Carnes y Afines, la Cámara Argentina de Industriales Productos Equinos y la Cámara Argentina de la Industria Frigorífica, la Federación Argentina de Entidades Empresarias del Autotransporte de Cargas, la Asociación de Plantadores de Arroz y el Colegio de Abogados de la Ciudad de Buenos Aires. ${ }^{32}$ Estas corporaciones, al cuestionar el Fondo Empresario, ponían en cuestión la representatividad de la CGE respecto del conjunto de la burguesía.

En el marco de esta ofensiva de las corporaciones opuestas a la CGE contra el aporte, se conformó el Comité de Acción Empresaria, que unificó por primera a los sectores de la burguesía en desacuerdo con el programa político-económico reformista que

${ }^{29}$ La Nación, 23 de abril de 1975.

${ }^{30}$ La Nación, 15 de marzo de 1975.

${ }^{31}$ La Nación, 17 de marzo de 1975.

${ }^{32}$ La Nación, 24 de marzo de 1975. 
Verónica Baudino, Alianzas y rupturas políticas entre capitalistas industriales durante el tercer gobierno peronista (1973-1976), Izquierdas, 40, junio 2018:82-100

se expresaba en la alianza CGE-CGT que sostenía al gobierno. Entre las entidades que actuaron desde el Comité para denunciar la creación del Fondo se encontraban la Cámara Argentina de la Construcción (CAMARCO), Cámara de Sociedades Anónimas (CAMSOCANON), Cámara de Comercio Automotor, Unión Comercial Argentina (UCA), Confederaciones Rurales Argentinas (CRA) y SRA. Aunque tuvo una corta vida, dado que el gobierno pronto desestimó avanzar con la medida, el acercamiento entre las corporaciones mencionadas sirvió de primer paso para los que luego se conocerá como APEGE (Asamblea Permanente de Entidades Gremiales Empresarias), la vanguardia del golpismo. La prédica de este polo opositor hacía mella a su vez en el interior del empresariado oficialista, avivando conflictos internos contra la CGE y la CINA.

Como respuesta a las reacciones adversas, el comité de presidencia de la CGE resolvió convocar a una reunión de presidentes y secretarios de las entidades adheridas de todo el país para analizar cuestiones relacionadas con el Fondo Sindical-Empresario y la Ley de Asociaciones Empresarias, y manifestó que había grupos minoritarios que "están orquestando una enconada campaña contra ese fondo" 33 .

La CINA, por su parte, pese a su inicial desacuerdo, parece haber llegado a un compromiso con la dirección de la CGE, exponiendo su apoyo a la creación del aporte obligatorio "como forma real del fortalecimiento de la acción empresaria organizada" ${ }^{4}$. Asimismo se entrevé una desautorización a gestiones personales de ciertos dirigentes de la institución, ya que la CINA señaló que ésta "se manifiesta únicamente a través de sus órganos representativos" 35 .

Finalmente, la CGE resolvió que no se abonen los aportes al fondo obreroempresario dado que el Ministerio de Trabajo no los había reglamentado. La entidad empresarial insistió en la necesidad de que el Congreso sancionase una ley al respecto, alegando que las organizaciones representativas deben contar con recursos suficientes para cumplir con eficacia su función, y que sería justo que fueran sostenidas por los integrantes del sector que representaban. ${ }^{36}$

Los enfrentamientos analizados, signados por la profundización de la crisis económica, nacional e internacional, y su correlato en la intensificación de la crisis política y de la lucha de clases, se ahondarán en los meses subsiguientes. El fracaso del violento plan de ajuste puesto en marcha por Celestino Rodrigo, que intentó descargar sobre los hombros de la clase obrera los costos de la crisis, marcará un punto de inflexión. El enfrentamiento de distintas fracciones de la clase dominante contra el gobierno, que asumirá un carácter abiertamente golpista en esta etapa, marcará la tónica del período que se abría. En él se pondría a prueba la unidad de la CGE, cuyo programa reformista y su apoyo al gobierno, se verían cuestionados por los empresarios que comenzaban a operar a favor del golpe de estado. La salida ofrecida por los golpistas comenzaría a atraer a un número importante de fracciones de la burguesía nacional que integraban la CGE, que

${ }^{33}$ La Nación, 18 de marzo de 1975.

${ }^{34}$ La Nación, 20 de marzo de 1975.

${ }^{35}$ La Nación, 20 de marzo de 1975.

${ }^{36}$ La Nación, 27 de marzo de 1975. 
Verónica Baudino, Alianzas y rupturas políticas entre capitalistas industriales durante el tercer gobierno peronista (1973-1976), Izquierdas, 40, junio 2018:82-100

empezaron a desafiliarse de la Confederación en un proceso que la llevaría a su virtual descomposición. Los viejos dirigentes de la UIA serán protagonistas de este proceso, resquebrajando, desde adentro, la representatividad de la CGE.

\section{Rodrigazo y después...}

El gobierno de María Estela Martínez de Perón realizó un violento giro en materia económica con el nombramiento de Celestino Rodrigo como ministro, que asumió el 2 de junio de 1975, con el apoyo de López Rega. El panorama económico era muy desfavorable. La crisis internacional hacía que se incrementen los precios de las importaciones, a la vez que se depreciaban los de las exportaciones argentinas. La consecuencia fue una drástica disminución de las reservas internacionales y la sobrevaluación de la moneda, que presionaba sobre una industria asediada por la competencia de los bienes importados. ${ }^{37}$

El programa que Rodrigo intentó aplicar consistía en crear las condiciones para aliviar la crisis de balanza de pagos. Por un lado, estableció una devaluación del 160\% para el tipo de cambio comercial y $100 \%$ para el financiero. Intentó reducir el déficit fiscal mediante un ajuste tarifario, que llegó al $181 \%$ para la nafta y $75 \%$ para el transporte urbano. Se reajustaron las tasas de interés mientras se liberaban las de depósitos a plazo fijo. Estos ajustes repercutirían sobre los precios de todas las mercancías, a los que no se puso ningún limite con los conocidos "acuerdos de precios". A lo que sí se pretendió imponer un límite fue a los salarios obreros, que se estaban negociando en paritarias: Rodrigo operó para reducir los aumentos salariales al 50\%, cuando antes de los ajustes tarifarios, Gómez Morales había pautado un 100\%. En suma, se lanzaba un profundo ajuste que buscaba enfriar la economía, reestablecer el equilibrio en la balanza de pagos y recuperar ingresos fiscales para aliviar la situación de las reservas. Tamaño ajuste sería pagado principalmente por los obreros, cuyos salarios reales se verían congelados en medio de los aumentos generalizados de todas las mercancías.

Sin embargo, más allá del apoyo explícito de sectores de la burguesía más concentrada, como el del Consejo Empresario Argentino, pronto el plan tropezó la resistencia de la clase obrera a ser la variable de ajuste. Tras los primeros anuncios comenzaron a estallar paros parciales y movilizaciones que evidenciaban una fuerte coordinación que superaba de la dirección de la burocracia sindical contra lo que se conoció como "Rodrigazo". 38

\footnotetext{
${ }^{37}$ Mario Rapoport, "Historia económica, social y política de la Argentina (1880-2000)." Buenos Aires, Macchi, 2000.

${ }^{38}$ Héctor Lobbe, La guerrilla fabril. Clase obrera e izquierda en la Coordinadora de Zona Norte del Gran Buenos Aires (1975-1976), Ediciones ryr, Buenos Aires, 2009; Pablo Kandel y Mario Monteverde. Entorno y caída. Planeta Argentina, 1976.
} 
Verónica Baudino, Alianzas y rupturas políticas entre capitalistas industriales durante el tercer gobierno peronista (1973-1976), Izquierdas, 40, junio 2018:82-100

El rechazo inmediato de las nuevas medidas por parte de la CGT no encontró igual actitud en la CGE. Los enfrentamientos internos entre quienes acordaban con el plan trazado por Rodrigo (CINA) y quienes no (socios históricos de la CGE) dificultaban el acuerdo acerca de la posición oficial de la entidad. Luego de semanas de silencio, el presidente de la CGE, Julio Broner, declaró en conferencia de prensa que la situación no tenía los tintes dramáticos que se esgrimían desde la conducción económica. Señaló que la situación no era peor que la de 1973, y sostuvo que el diagnóstico dramático efectuado por Celestino Rodrigo tenía por objetivo justificar el "anti popular" plan económico puesto en marcha. ${ }^{39}$ La ofensiva de la CGE contra Rodrigo suscitó la reacción de los antiguos miembros de la UIA que dominaban la CINA, quienes expresaban la necesidad de un cambio de rumbo ante el fracaso del Pacto Social, pronunciándose en favor del "Rodrigazo".

La resistencia obrera ante el plan derivó en el fin del mandato de Rodrigo y el intento de un nuevo Pacto social, a las órdenes de Antonio Cafiero como Ministro de Economía. Su política económica consistiría en una mini devaluación, refinanciación, expansión del crédito y duplicación del salario familiar. La dirección nacional de la CGE declaró que los lineamientos de la política anunciada por el ministro de Economía coincidían en lo fundamental con el programa de emergencia aprobado por el Consejo Superior de la entidad. No obstante, esa opinión no representaba al conjunto de la CGE. La CINA, también mostró sus disidencias, como en ocasión del Plan Rodrigo, agudizando la distancia entre ambos sectores.

En efecto, a contramano del tono más conciliador de la dirección nacional de la CGE, la CINA iba endureciendo su discurso, atizada por la intensa campaña que habían emprendido los empresarios golpistas nucleados en APEGE $^{40}$ contra el gobierno y la Confederación General Económica. ${ }^{41}$ CINA y APEGE confluían en el reclamo del restablecimiento del orden a toda costa y bregaban más o menos abiertamente por la consumación del golpe de Estado. Su posición tuvo fuertes repercusiones dentro de la propia Confederación, que comenzó un largo proceso de desmembramiento en el que varias se sus fracciones se fueron sumando a la alianza pro militar.

\section{Ocaso de la CGE}

Un creciente número de corporaciones empresarias regionales se fueron desafiliando de la CGE al calor de la ofensiva golpista de APEGE, entre septiembre y diciembre de 1975. COPAL, conformada en estos meses con cámaras provenientes de la CINA, confluyó desde la primera hora en la Asamblea. También el Movimiento de Unidad

\footnotetext{
${ }^{39}$ Cronista Comercial, 15 de julio de 1975.

${ }^{40}$ Asamblea Permanente de Entidades Gremiales Empresarias, formada a fines de 1975 y que reunía a las fracciones empresarias que impulsaron el golpe de Estado. Su programa político se asentaba en un marcado enfrentamiento con la estrategia reformista de la CGE. Estaba compuesta, entre otras corporaciones por los ruralistas de CRA y SRA.

${ }^{41}$ Verónica Baudino, y Gonzalo Sanz Cerbino, "Las corporaciones agrarias e industriales frente al golpe del '76: apuntes para la reconstrucción de la Fuerza Social Contrarrevolucionaria”, Instituto Gino Germani, UBA, Buenos Aires, 2011.
} 
Verónica Baudino, Alianzas y rupturas políticas entre capitalistas industriales durante el tercer gobierno peronista (1973-1976), Izquierdas, 40, junio 2018:82-100

Industrial (MUI), integrado entre otras cámaras por la ADIC, que pertenecía a la CINA, resolvió en diciembre de 1975 "apoyar las reuniones organizadas por APEGE" ${ }^{\text {"2 }}$. Otro miembro del MUI, FEBA, que se desafilió de la CGE en 1973, participó de las reuniones en las que se conformó APEGE y formó parte de su dirección.

La desafiliación en esos meses de la Bolsa de Cereales de Buenos Aires y la Unión General de Tamberos, significaba la pérdida para la CGE de las últimas corporaciones de la burguesía agraria bajo su órbita. ${ }^{43}$ La Federación Agraria Argentina, miembro histórico de la CGE, se había desafiliado de la corporación nacional a mediados de julio de 1975, resultado de un largo proceso de enfrentamiento con el gobierno nacional a raíz de los precios agrarios fijados oficialmente, que la había llevado a confluir con CRA y SRA en cuatro de los cinco paros agrarios realizados ese año.

Una de las disidencias más importantes es la de las confederaciones económicas de las provincias del nordeste argentino, todas ellas regionales provinciales de la CGE, que posteriormente conformarían el Movimiento Empresario del Interior (MEDI). El movimiento disidente comenzó a gestarse en oposición a la concertación acordada por la CGE con el ministro de Economía Cafiero. La oposición había sido impulsada por la Federación Económica de Tucumán, que buscaba acaudillar a otras regionales enfrentadas a la dirección nacional de la entidad y a su política de concertación con el gobierno peronista. Estas federaciones publicaron una solicitada en la que enumeraban los "nefastos" resultados de la política económica peronista: "lucha de clases, fortalecimiento de la subversión"; "se llevó la política de distribución del ingreso hasta el límite de paralizar el proceso de inversión"; descapitalización de la empresa privada, inflación, "disminución de la eficiencia, de la productividad y del empleo de los recursos disponibles"; "desaliento de la actividad empresaria"; "macrocefalia e hipertrofia del aparato estatal"; "avance de las funciones estatales sobre la iniciativa privada"; "ineficiencia del aparato estatal". Confrontaban, a su vez, con lo que calificaban como una "filosofía importada, colectivizante y estatizadora, que tiende a anular los valores más trascendentes de la personalidad y el estilo de vida de los argentinos".

El sentido de las declaraciones coincidía con el programa de APEGE. La exhaustiva campaña emprendida por los empresarios golpistas, para cercenar las bases de la CGE y arrebatar el apoyo de estas fracciones de la burguesía al gobierno estaba surtiendo efecto. Ante la profundización de la crisis, el reformismo va perdiendo apoyo entre los empresarios, y su expresión corporativa, la CGE, comienza a desmembrarse. No es casual entonces, que sean estas regionales de la CGE las que, desobedeciendo la línea oficial de la dirección nacional, se sumen en febrero de 1976 al lock out impulsado por APEGE.

En los mismos meses, la Federación de Asociaciones de Bancos Argentinos, que reunía a dos instituciones de la banca privada nacional (ADEBA -Asociación de Bancos Argentinos- y la Asociación de Bancos del Interior), resolvió desafiliarse de la CGE,

${ }^{42}$ La Nación, 12 de noviembre de 1975.

${ }^{43}$ La Nación, 8 de septiembre de 1975. 
Verónica Baudino, Alianzas y rupturas políticas entre capitalistas industriales durante el tercer gobierno peronista (1973-1976), Izquierdas, 40, junio 2018:82-100

conformar la Unión de Entidades Financieras Argentinas (UDEFA) y posteriormente confluir con APEGE. ${ }^{44}$

La convocatoria de APEGE a un lock out para el 16 de febrero de 1976 marcó el final de la CGE. A la crisis interna de la entidad se sumó la atracción que ejercía el polo de los empresarios golpistas, generando una ola de desafiliaciones e indisciplina entre los socios, con decenas de agrupaciones que decidieron sumarse al lock out a pesar de la línea contraria planteada por la dirección nacional de la CGE. Asistimos, de esta manera, a un proceso de descomposición de la confederación, como expresión política de la agudización de la crisis económica y la necesidad de relanzar la acumulación de capital por la vía de la caída del precio de la fuerza de trabajo y la concentración de capitales, opuestos al programa reformista.

A principios de febrero de 1976 una asamblea de la filial bonaerense de la CGE realizada en Olavarría, con la presencia de más de 100 delegados, condenó severamente la política económica del gobierno y se dispuso ejecutar "medidas concretas de protesta, incluyendo un paro general de actividades en todo el territorio de la provincia". A su vez, se dispuso sustentar esa posición crítica en el seno de la conducción nacional de la CGE. En la declaración se caracterizó negativamente la situación económica, siendo expresión de ello la caída de la productividad y de la producción, la iliquidez, la hipertrofia de la burocracia estatal y la "anarquía laboral", entre otras. ${ }^{45}$

En paralelo, el Consejo Superior de la CGE se veía presionado a emitir una declaración sobre la situación política, que dé respuesta a la inquietud de las bases ante el inminente lock out de APEGE. Finalmente, la CGE resolvió declarar el estado de emergencia nacional, en un documento que expresó sus críticas al gobierno y que disponía la posibilidad de convocar a medidas de protesta, que serían resueltas oportunamente su conducción. El documento emitido condenaba la inflación, a la que no se atacaría correctamente, y criticaba el aumento de los presupuestos nacionales, provinciales y municipales, que se sostendrían en el incremento de los impuestos. También se refirió negativamente al "desorden laboral", alentado por la Ley de Contrato de Trabajo y por la actitud parcial del Ministerio de Trabajo. Llamaba, en ese sentido, a "reestablecer la disciplina en la producción". Por último, criticó la "inseguridad empresaria, fruto de la violencia reiterada". ${ }^{46}$

Aunque la CGE no planteaba una confluencia en la acción con APEGE, coincidía con sus exigencias. De hecho, la CINA, publicó una solicitada en la que caracterizaba la situación como "grave emergencia nacional", y sostenía que estaba en peligro la Nación misma. Señalaba, a su vez, que era necesario detener el "desborde de poder" del sindicalismo. Es decir, coincidían con APEGE en resaltar la gravedad de la crisis, argumento que en estos últimos funcionaba como justificativo del golpe. La reversión del proceso demandaría el sacrificio de todos, pero, sin embargo "es imprescindible deponer

${ }^{44}$ La Nación, 19 de diciembre de 1975.

${ }^{45}$ La Nación, 2 de febrero de 1976.

${ }^{46}$ La Nación, 4 de febrero de 1976. 
Verónica Baudino, Alianzas y rupturas políticas entre capitalistas industriales durante el tercer gobierno peronista (1973-1976), Izquierdas, 40, junio 2018:82-100

toda actitud tendiente a defender sólo el interés sectorial por encima de los intereses de la Nación toda". Esta frase parece referirse al paro de APEGE, al que la CINA no adhirió. ${ }^{47}$

Las concesiones discursivas efectuadas por la dirección de la CGE no alcanzaron a contener la sangría que estaba sufriendo. La atracción que ejercía el programa de APEGE, y la desconfianza generada por una dirigencia que había avalado la política oficial hasta no mucho tiempo atrás, pesaron más. Durante las dos primeras semanas de febrero una cantidad importante de corporaciones se desafiliaron de la CGE, criticando a su dirección y plegándose al plan. La Liga de Comercio, Propiedad e Industria de Punta Alta ${ }^{48}$, la Corporación de la Industria y el Comercio de Bahía Blanca ${ }^{49}$, la Cámara de la Industria Curtidora Argentina, el Centro de Industria y Comercio de Río Colorado ${ }^{50}$, la Cámara Comercial e Industrial de Tandil, la Cámara Empresaria del Transporte Automotor de Pasajeros $^{51}$ y la Cámara Argentina de Mercerías y Anexos ${ }^{52}$, se distanciaron de la CGE.

La CGE se vio constreñida a convocar medidas de protesta para contrarrestar el efecto causado por el lock out de APEGE. El 11 de febrero se resolvió llamar a una "semana de protesta del empresariado nacional" entre el 21 y el 28 de ese mes. La elección de la fecha no era casual: las medidas de fuerza organizadas por APEGE se darían cita tan sólo seis días después del anuncio de la CGE. La medida se efectivizaría con la realización de apagones o paros simbólicos, actos públicos y manifestaciones. ${ }^{53}$

A pesar de ello, el desmembramiento de la confederación no parecía tener fin. En los días previos al 16 de febrero se conoció el pronunciamiento de las diez regionales provinciales de la CGE que habían manifestado previamente sus disidencias. Las Federaciones de Santa Cruz, La Rioja, San Juan, Mendoza, Salta, Jujuy, Misiones, Córdoba, Tucumán y Catamarca, hicieron público que se sumaban a la medida convocada por APEGE. Frente al hecho consumado, la CGE no tuvo más remedio que virar su posición respecto a la medida. Luego de varias solicitadas oponiéndose al lock out, finalmente, su vicepresidente primero y su secretario, en conferencia de prensa, anunciaron que "no deseaban entrar en competencias con otras entidades", y que dejaban en libertad de acción a sus afiliados para que adhieran al paro empresario. ${ }^{54}$

En marzo la crisis interna de la CGE continuó desarrollándose. El 7 se conoció la renuncia de su presidente y 5 vocales, y algunos días después la convocatoria a un lock out en la Provincia de Buenos Aires, por 48 horas, que tuvo escasa repercusión. ${ }^{55}$ El 14 de marzo se constituyó un nuevo reagrupamiento empresario en el interior de la CGE, el MEDI, integrado por las Federaciones de Catamarca, Jujuy, La Rioja, Mendoza, Misiones, Salta, San Juan y Tucumán (aquellas que se habían sumado al paro de APEGE). El nuevo

\footnotetext{
${ }^{47}$ La Nación, 11 de febrero de 1976.

${ }^{48}$ La Nación, 6 de febrero de 1976.

${ }^{49}$ La Nación, 8 de febrero de 1976.

${ }^{50}$ La Nación, 15 de febrero de 1976.

${ }^{51}$ La Nación, 24 de febrero de 1976.

52 La Nación, 17 de marzo de 1976.

${ }^{53}$ La Nación, 12 de febrero de 1976.

${ }^{54}$ La Nación, 15 de febrero de 1976.

${ }^{55}$ La Nación, 9 de marzo de 1976.
} 
Verónica Baudino, Alianzas y rupturas políticas entre capitalistas industriales durante el tercer gobierno peronista (1973-1976), Izquierdas, 40, junio 2018:82-100

ente exigió en un documento la renuncia de las autoridades de las tres cámaras que conformaban la CGE: Confederación General del Comercio, Confederación General de la Producción y Confederación Industrial Argentina. A su vez, se exigió la renuncia de la dirección nacional de la CGE. Entre otras razones, argumentaron que esa conducción había avalado las políticas que llevaron al empresariado a la quiebra, "propiciando esquemas ajenos a nuestra mentalidad, imponiendo ideologías estatizadoras y colectivizantes" 56 . Un día después, la filial Córdoba de la CGE criticó a la conducción nacional de la entidad, señalando que no había defendido a los pequeños empresarios por su alianza con el gobierno, y que eso hacía mermar la confianza de sus bases. Reclamaba de la confederación "auténtica independencia" y la renuncia de sus autoridades. ${ }^{57}$

\section{Conclusiones}

La magnitud alcanzada por la crisis política desde el Cordobazo evidenciaba la necesidad de incrementar las concesiones económicas y simbólicas a las masas para reencausarlas en la senda institucional. El peronismo aparecía, así, como la alternativa política más racional frente a la coyuntura planteada. Su capacidad para contener las tendencias insurreccionales no podría haber sido posible si no se hubiese estado en un momento de auge económico gracias al alza excepcional de la renta agraria que habilitaba una nueva experiencia reformista. La posibilidad de distribuir riquezas a un número mayor de capitales individuales y la contención de la clase obrera movilizada explican el apoyo de la mayoría de los sectores burgueses. La unificación de la CGE y la UIA detrás del apoyo al Pacto social se inscriben en esta particular situación.

El fin de la bonanza económica y la muerte de Perón, volvieron a poner sobre el tapete las disputas políticas inter capitalistas y el reavivamiento de la marcha de las tendencias insurreccionales de la clase obrera. La unidad de la UIA con la CGE comenzó a resquebrajarse. Ex socios de la UIA declararon públicamente su desacuerdo con el Pacto Social. La política de concertación llevaba el sello de Gelbard y la CGE, implicando la exposición de disidencias de parte de la ex UIA con su nueva dirección nacional. El plan de Celestino Rodrigo ensayado en junio de 1975 marcó definitivamente la ruptura. El acuerdo solapado de dirigentes de la ex UIA con la mega devaluación y congelamiento salarial, expresaba que ya no había lugar para el reformismo.

Paralelamente, se iba gestando la alianza golpista, encabezado por APEGE. La atracción ejercida sobre muchos de los ex integrantes de la UIA, y en tanto proceso más general, sobre el conjunto de la CGE, generó la inevitable descomposición de la alianza reformista. Buena parte de las corporaciones empresarias en todas las ramas y capas, puestas frente a la posibilidad de perderlo todo ante el peligro revolucionario (el "caos"), se alinearon con el programa golpista delineado por APEGE. Era necesario un profundo ajuste de la economía, que iba a recaer en buena parte, sobre los hombros de una clase

\footnotetext{
${ }^{56}$ La Nación, 15 de marzo de 1976.
}

${ }^{57}$ La Nación, 16 de febrero de 1976 
Verónica Baudino, Alianzas y rupturas políticas entre capitalistas industriales durante el tercer gobierno peronista (1973-1976), Izquierdas, 40, junio 2018:82-100

obrera reacia a pagar los costos de la crisis. Por esa razón, la imposición del programa económico que implicaba el disciplinamiento de la clase trabajadora y la expoliación de sus condiciones de vida demandaba un estado de excepción y una brutal represión, sancionados desde el 24 de marzo de 1976.

\section{Bibliografía}

- Aberlardo Ramos, La era del peronismo, 1943-1989, Buenos Aires, Ediciones del Mar Dulce, 1990; Rodolfo Puiggrós, El peronismo: sus causas, Buenos Aires, Cepe, 1972

- Alejandro. Horowicz, Los cuatro peronismos, Edhasa, Buenos Aires, 2007

- Beba Balvé Beatriz y Beatríz Balvé, El'69 huelga política de masas: rosariazo, Cordobazo, rosariazo. Razón y Revolución-CICSO, 2005

- Carlos H. Acuña, "Las contradicciones de la burguesía en el centro de la lucha entre el autoritarismo y la democracia (1955-1983)". Realidad Económica, no. 138 (1996), p. 1848.

- Carlos Leyba, Economía y política en el tercer gobierno de Perón. Editorial Biblos, 2003; Guido Di Tella y Luis Justo, Perón-Perón, 1973-1976. Editorial Sudamericana, 1983.

- Claudio Belini, Convenciendo al capital: Peronismo, burocracia, empresarios y política industrial, 1943-1955, Ediciones Imago Mundi, 2014

- Daniel Muchnik, Argentina modelo: de la furia a la resignación: economía y política entre 1973 y 1998. Ediciones Manantial, 1998

- Elmar Altvater, "Estado y capitalismo. Notas sobre algunos problemas del intervencionismo estatal.", Cuadernos políticos 9, 1976.

- Ernesto Laclau, "Hacia una teoría del populismo", E. Laclau, Política e ideología en la teoría marxista. Capitalismo, fascismo, populismo. Madrid. Siglo Veintiuno, 1978

- Guillermo O'donnell, 1966-1973, el estado burocrático autoritario: triunfos, derrotas y crisis. Editorial de Belgrano, 1982.

- Héctor Lobbe, La guerrilla fabril. Clase obrera e izquierda en la Coordinadora de Zona Norte del Gran Buenos Aires (1975-1976), Ediciones ryr, Buenos Aires, 2009.

- Hernán Ramírez, Corporaciones en el poder. Institutos y acción política en Brasil y Argentina. IPÊS, FIEL y Fundación Mediterránea, Lenguaje Claro Editora, Buenos Aires, 2007

- James Brennan y Marcelo Rougier, Perón y la burguesía argentina. El proyecto de un capitalismo nacional y sus límites (1946-1976), Editorial Lenguaje Claro, Buenos Aires, 2013

- James Brennan, El Cordobazo, Sudamericana, Buenos Aires. 1996.

- Javier Lindenboim, "El empresariado industrial argentino y sus organizaciones gremiales entre 1930 y 1946." Desarrollo Económico 16.62 (1976): 163-201.

- John William Freels, El sector industrial en la política nacional, EUDEBA, Editorial Universitaria de Buenos Aires, 1970

- Jorge Schvarzer, Empresarios del pasado: la Unión industrial argentina. Buenos Aires: Cisea, 1991.

- José Luis De Ímaz, Los que mandan, Eudeba, Buenos Aires, 1965 
Verónica Baudino, Alianzas y rupturas políticas entre capitalistas industriales durante el tercer gobierno peronista (1973-1976), Izquierdas, 40, junio 2018:82-100

- Juan Iñigo Carrera, La formación económica de la sociedad argentina, Imago Mundi, Buenos Aires, 2007.

- Liliana De Riz, Retorno y derrumbe: el último gobierno peronista. Vol. 75. Hyspamerica, 1987; Mónica Peralta-Ramos, La economía política argentina: poder y clases sociales, 1930-2006. Fondo De Cultura Económica USA, 2007.

- Marcelo Rougie y Martín Fiszbein. La frustración de un proyecto económico: el gobierno peronista de 1973-1976. Ediciones Manantial, 2006.

- Mariana Heredia, "El proceso como bisagra. Emergencia y consolidación del liberalismo tecnocrático: FIEL, FM y CEMA." Alfredo Pucciarelli (dir.), Empresarios, tecnócratas y militares. La trama corporativa de la última dictadura. Buenos Aires: Siglo XXI, 2004.

- Mario Rapoport, "Historia económica, social y política de la Argentina (18802000)." Buenos Aires, Macchi, 2000.

- Marx. Karl. El Capital, Siglo XIX, Buenos Aires, 2002.

- Milcíades Peña, "Apuntes para una historia del peronismo. El gobierno del 'como si': 1946- 1955”, Revista Fichas de Investigación Económica y Social, nro. 7, 1965, pp. 3-21

- Mirta Palomino, "Tradición y poder: La sociedad rural argentina (1955-1983). Buenos Aires: CISEA/Grupo Editor Latinoamericano, 1988

- Pablo Kandel y Mario Monteverde. Entorno y caída. Planeta Argentina, 1976.

- Ricardo Sidicaro, "Consideraciones sociológicas sobre las relaciones entre el peronismo y la clase obrera en Argentina, 1943-1955", Moira Mackinnon y Mario Alberto Petrone [comps.], Populismo y neopopulismo, el problema de la Cenicienta. Buenos Aires. Eudeba, 1998

- Roque Caggiano, Notas sobre el desarrollo de la burguesía nacional: La Confederación General de la Industria y la Unión Industrial en el período 1957-1973, Centro de Estudios Urbanos y Regionales, Instituto Torcuato Di Tella, 1975

- Verónica Baudino, La estrategia de la UIA 1966-1976, Tesis doctoral, Facultad de Filosofía y Letras de la UBA, 2012

- Verónica Baudino, y Gonzalo Sanz Cerbino, "Las corporaciones agrarias e industriales frente al golpe del '76: apuntes para la reconstrucción de la Fuerza Social Contrarrevolucionaria", Instituto Gino Germani, UBA, Buenos Aires, 2011.

\section{Fuentes consultadas}

- La Nación, varios años

- Clarín, varios años

- Cronista comercial, varios años

- Memoria y Balance de la CGE, varios años

- Memoria y Balance de la UIA, varios años

- Revista de la UIA

- Boletín Informativo de la CGE

- Congreso General de la Industria

- Publicaciones del Instituto Investigaciones Económicas y Financieras 